\title{
Correction to: Bioclimatic pattern in a Mediterranean mountain area: assessment from a classification approach on a regional scale
}

\author{
Maurizio Cutini ${ }^{1} \cdot$ Marzialetti Flavio $^{2} \cdot$ Barbato Giuliana $^{3} \cdot$ Rianna Guido $^{3} \cdot$ Theurillat Jean-Paul $^{4}$
}

Published online: 1 March 2021

(C) ISB 2021

\section{Correction to: International Journal of Biometeorology} https://doi.org/10.1007/s00484-021-02089-x

This correction stands to correct the contributor name, Maurizio Cutini. The original article was published showing the contributor's first and last name in the wrong order. The original article has been corrected.

The online version of the original article can be found at https://doi.org/ 10.1007/s00484-021-02089-x

Marzialetti Flavio

flavio.marzialetti@unimol.it

Maurizio Cutini

maurizio.cutini@uniroma3.it

Barbato Giuliana

giuliana.barbato@cmcc.it

Rianna Guido

guido.rianna@cmcc.it

Theurillat Jean-Paul

jean-paul.theurillat@unige.it
Department of Science, University of Roma Tre, Rome, Italy

2 EnviX-Lab, Dipartimento di Bioscienze e Territorio, Universita degli studi del Molise, Pesche, Isernia, Italy

3 REMHI Regional Models and Geo-Hydrological Impacts Research Division, CMCC Foundation Euro-Mediterranean Center on Climate Change, Capua, CE, Italy

Centre Alpien de Phytogéographie, Fondation J.-M. Aubert, Champex-Lac, Switzerland and Department of Botany and Plant Biology, Section of Biology, University of Geneva, Chambésy, Geneva, Switzerland 